\title{
Severe Unusual Presentation of Fat Necrosis in Neonatal Age: A Case Report
}

\author{
Shatha M. Albokhari, MD, SB-PEDS, and Nouran M. Abu-Ouf, MD, Msc (MED Sci)
}

Department of Pediatrics, Faculty of Medicine

King Abdulaziz University, Jeddah, Saudi Arabia

\author{
Correspondence \\ Dr. Shatha M. Albokhari \\ P.O. Box 80270, Jeddah 21589, Saudi Arabia \\ e.M: albokhari_sh@yahoo.com \\ Submission: 25 May 2015 \\ Accepted: 6 July 2015
}

\section{Citation}

Albokhari SA, Abu-Ouf NM. Severe unusual presentation of fat necrosis in neonatal age: a case report. JKAU Med Sci 2015; 22 (4): 53-57. DOI: 10.4197/Med. 22.4.7

\begin{abstract}
Fat necrosis in newborns is estimated to be a rare and self-healing (limited) condition that affects full term or post term newborns in the first few weeks of life. The etiology is not clear and even then this disorder is linked with hypothermia, thrombocytopenia, anemia, gestational diabetes, neonatal hypoxia, and obstetric trauma, preeclampsia and maternal exposure to cocaine or calcium channel blockers usage at the time of pregnancy. Hypercalcemia is considered the most serious, albeit rare, complication appearing a maximum six months after skin lesions.
\end{abstract}

\section{Keywords}

Fat; Necrosis; Neonate; Hypercalcemia; Hypothermia; Selflimited; Asphyxia

\section{Introduction}

ruise in 1875 had described subcutaneous fat necrosis of a newborn and initially it was known as scleroderma of the newborn infant. It was considered an unusual transient condition. It is usually seen in term to post term neonates experiencing perinatal complications in the initial few weeks of life. Fat necrosis may be related to hypercalcemia and it is a transient disorder of the adipose tissue developed after trauma or asphyxia at the time of birth. Furthermore, it occurs due to hypoxia and hypothermia in the neonatal period, and there may be additional predisposing factors due to fat necrosis occurrence in all infants at risk of these conditions. The nodules of subcutaneous fat necrosis are normally self-limited but the hypercalcemia may pose a fatal risk if it is not detected or considered ${ }^{[1]}$.

There are 12 cases depicting fat necrosis, 1\% of the infants having been treated for moderate hypothermia and enrolled with the UK TOBY Cooling Register. Since previous accounts were actually the rare anecdotal cases, the occurrence of subcutaneous fat necrosis in cooled infants may appear to be greater when compared to that reported earlier after perinatal asphyxia, and yet the true complication incidence after perinatal asphyxia is unknown due to scarcity of data in the literature. Hypercalcemia is the factor for severe but infrequent complications ${ }^{[2]}$.

\section{Case Report}

Our patient was a full term male infant, delivered via spontaneous vaginal delivery to a pre-eclamptic mother who was on anti-hypertension medication. Delivery was complicated by shoulder dystocia. Birth weight was $4.2 \mathrm{~kg}$ eventually requiring neonatal intensive care unit (NICU) admission due to birth asphyxia, respiratory distress syndrome and signs of neonatal sepsis. Mechanically ventilated for 15 days. At the 5th day of life nodular lesions started to emerge on his lower back over the vertebral column, lesions indurated and erythematous, typically suggestive of abscess. Ultrasonography of the back was done and showed hyper-echoic soft tissue not consistent with abscess with cystic areas at size of $2.1 \times 2.2 \mathrm{~cm}$. At 
age 28 days he was discharged from the NICU with no documentation of lesion improvement.

At age of 2 months he presented to our Emergency Department due to poor feeding and vomiting after feeds, with no other systemic manifestations reported by the mother.

On examination he was febrile $37.9^{\circ} \mathrm{C}$, with stable vital signs and normal growth parameters for age and no dysmorphic features. His examination revealed an alert easily irritated baby otherwise normal. Normal male genitalia with bilateral descended testes. Other systemic examination was normal.

Upon examining his back, a few nodules that were hard, tender, reddish/ purple in colour with various sizes along the spine were detected (Figs. 1, 2 and 3), two other mass felt on the right and left deltoids and

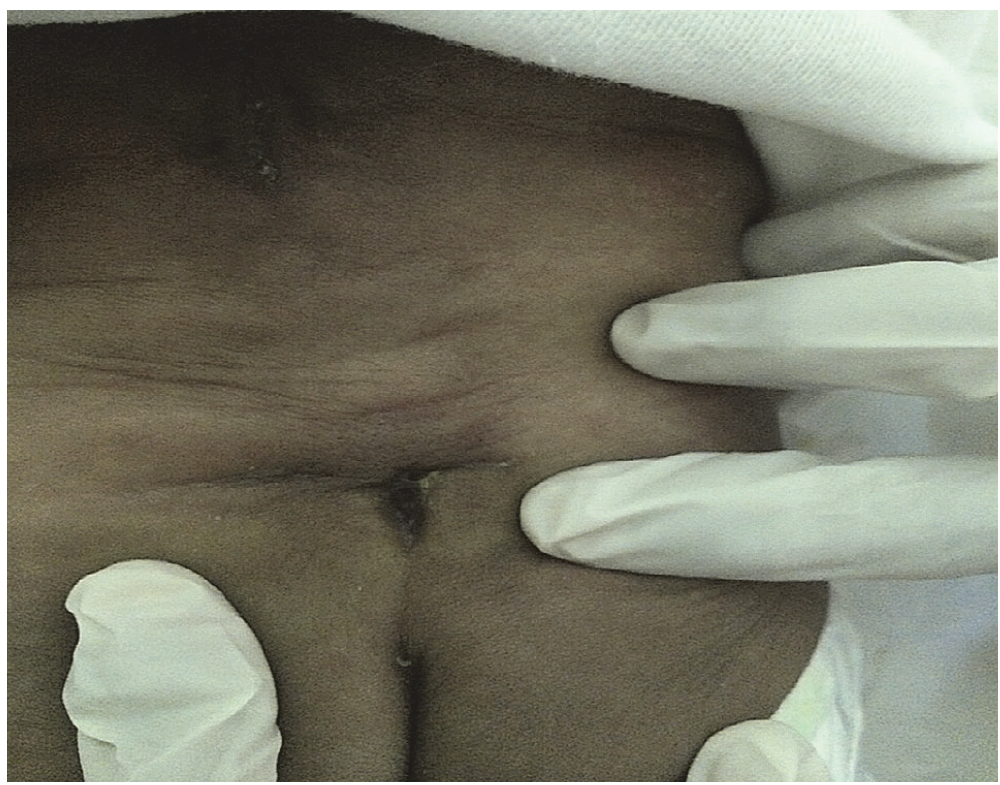

Figure 1. Skin lesions on the lower back caused by subcutaneous fat necrosis of one of the infants: erythematous plaques and nodules on the back with pussy discharge that mimic abscess.

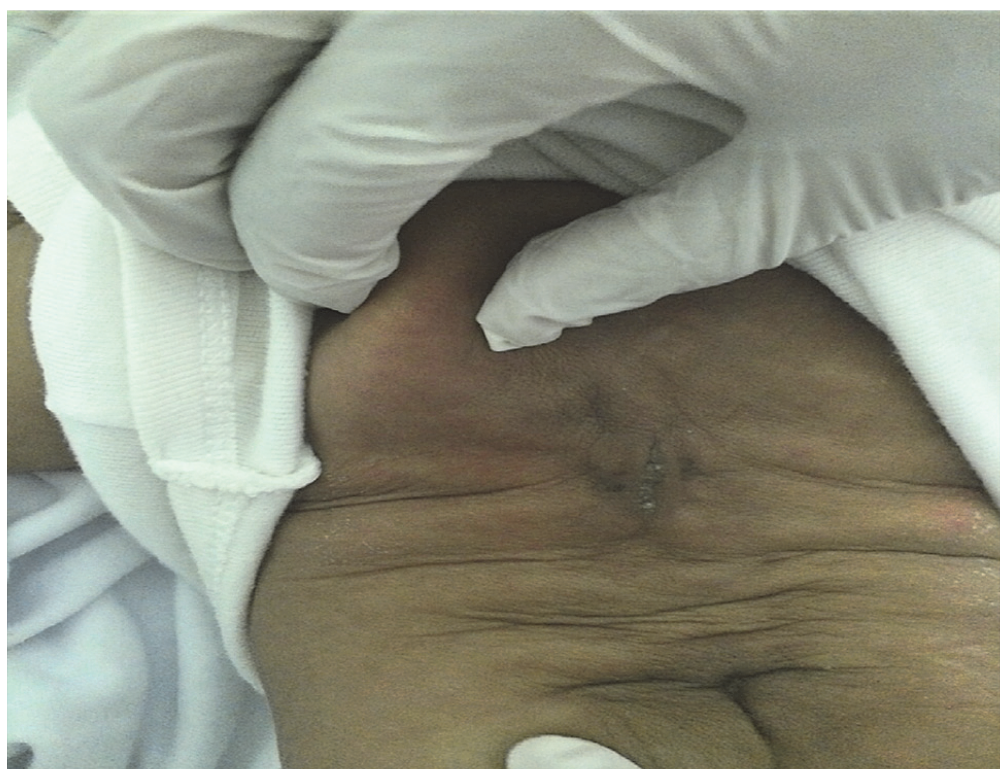

Figure 2. Skin lesions on the upper back caused by subcutaneous fat necrosis of one of the infants: erythematous plaques and nodules on the back with pussy discharge that mimic abscess. 


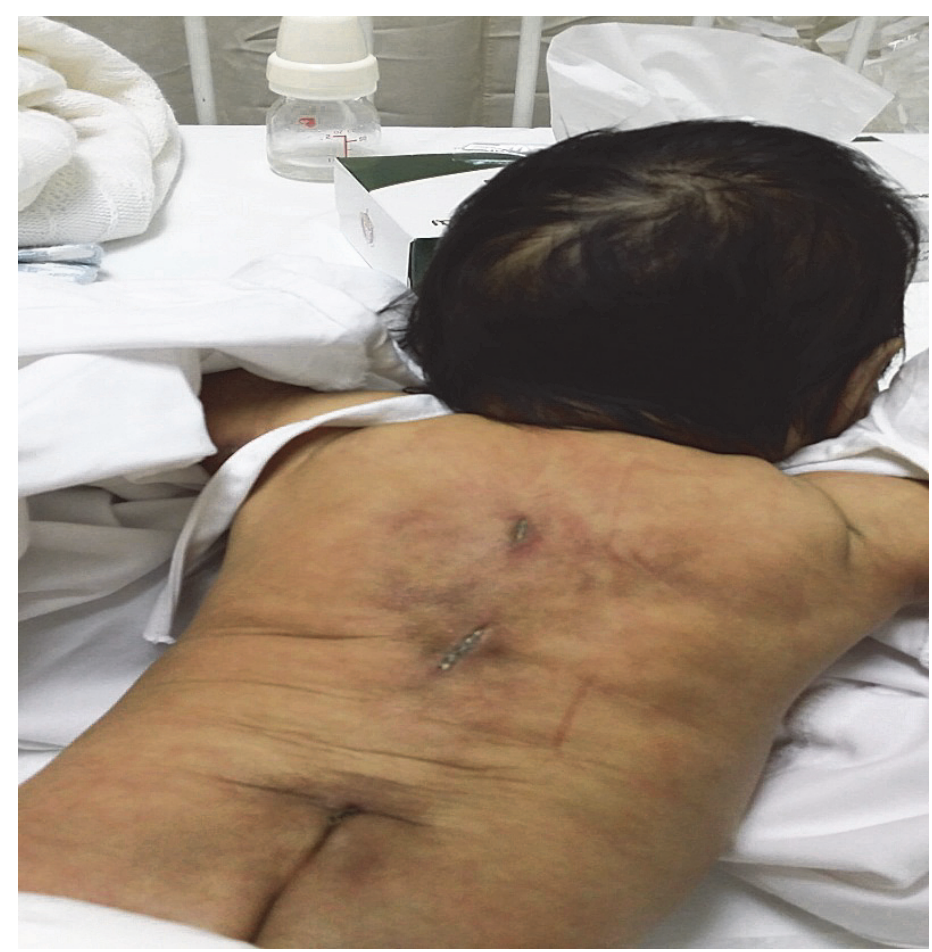

Figure 3. Skin lesions along the spine of the patient with pussy discharge mimicking abscess.

one more just below the left scapula. Small multiple lesions were felt under the chin.

Upon investigating the patient, he was found to have high neutrophil, lymphocyte and eosinophilic count with a white blood cell (WBC) count of $23.3 \mathrm{k} /$ $\mathrm{uL}$, normal haemoglobin and platelets, his bone profile showed Calcium of $4.08 \mathrm{mmol} / \mathrm{L}$, Phosphate 1.08 $\mathrm{mmol} / \mathrm{L}$, Alkaline phosphatase $228 \mathrm{U} / \mathrm{L}$ and Parathyroid hormone of $0.143 \mathrm{U} / \mathrm{L}$.

He was partially screened for sepsis that showed the following: Erythrocyte Sedimentation Rate $76 \mathrm{~mm} / \mathrm{H}, \mathrm{C}-$ reactive Protein $10.8 \mathrm{mg} / \mathrm{L}$. Blood culture was negative as was Methicillin-Resistant Staphylococcus Aureus screen. A deep wound swab was sent for culture which showed heavy growth of Pseudomonas aeruginosa. Bone scan was done and showed no evidence of osteomyelitis. Lumbosacral spine magnetic resonance imaging (MRI) was done to rule out any deep seated lesions and it showed a normal study. Immune studies were also considered to rule out immunodeficiency and tests revealed normal results.

Additionally, the patient has been evaluated by endocrinology who advised good hydration and calcitonin $4 \mathrm{u} / \mathrm{kg}$ dose subcutaneously every $12 \mathrm{hrs}$ which was increased to 8 Units due to persistent high calcium levels in the following week and Phosphate maintenance dose started. Over the following few days his calcium level started to normalize with static levels of $(2.14-2.19 \mathrm{mmol} / \mathrm{L})$.

He was followed up frequently in the clinic throughout the next few months and slow healing of the lesions was noted with good growth parameters.

\section{Discussion}

The following risk factors are attributed to the fat necrosis of newborns despite the unclear etiology: Neonatal hypoxia, local trauma, thrombocytopenia, anemia and hypothermia are on the neonatal side. Gestational diabetes and pre-eclampsia during pregnancy are from the side of maternal factors yet mostly subcutaneous fat necrosis would not be exposed to babies by these factors and despite the fact of unknown cause of fat necrosis ${ }^{[3,4]}$.

Neonates of full-term to post-term are affected by newborn subcutaneous fat necrosis. Circumscribed nodules and plaques overlaying bony prominences on the trunk, buttocks, extremities and cheeks, and areas both mobile and firm are especially observed by the technicians. The fluctuant and draining nodule 
development is found to be existent. Skin thus affected by subcutaneous fat liquefies and multicystic plaques may undergo epidermal necrosis and become taut.

Liquefaction may be severe and tough in certain cases. On physical examination, complications like scarring, pain and hypercalcemia are noted. The risk factors commonly attributed to the development of subcutaneous fat necrosis include birth asphyxia and hypothermia ${ }^{[5,6]}$.

Scleremaneonatorum is associated with the main clinical differential diagnosis of subcutaneous fat necrosis. Depending on physical examination and history, these two identities are distinct from each other. Skin biopsy becomes handy when the clinical diagnosis is not typical. Skin biopsy of subcutaneous fat necrosis exhibited necrosis of fat, multinucleated giant cells having granuloma formation and lipocytes ${ }^{[7]}$.

The pathogenesis involving hypercalcemia with respect to subcutaneous fat necrosis is very cumbersome. The mechanism suggested will be formed with elevated prostaglandin E and elevated parathyroid hormone levels. Depending on the clinical and level of serum in ionized calcium, the management of hypercalcemia is undertaken in subcutaneous fat necrosis. Aggressive management is required when the patient shows symptoms like irritability or lethargy. Adequate hydration, a low calcium diet, a calcium wasting diuretic (furosemide) and vitamin $D$ restriction may be required to undertake the treatment of subcutaneous fat necrosis with hypercalcemia ${ }^{[8]}$.

\section{Conflict of Interest}

The authors have no conflict of interest.

\section{Disclosure}

None of the authors received any type of commercial support either in forms of compensation or financial for this study. They have no financial interest in any of the products or devices, or drugs mentioned in this article.

\section{Ethical Approval}

Obtained.

\section{References}

[1] Shidhani KS, Maani AS, Jabri AT. A rare presentation of a new born with subcutaneous fat necrosis. Oman Med J 2013; 28(4): 1-3.
[2] Lara LG, Villa AV, Rivas MM, Capella MS, Prada F, Ensenat MA. Subcutaneous fat necrosis of the new born: Report of five cases. Pediatrics Neonatology 2014; 4: 1-4.

[3] Gomes MP, Porro AM, Enokihara MM, Floriano MC. Subcutaneous fat necrosis of the new born: clinical manifestations in two cases. An Bras Dermatol 2013; 88(6 Suppl 1): 154-157.

[4] Mahé E, Girszyn N, Hadj-Rabia S, Bodemer C, Hamel-Teillac D, Deprost Y. Subcutaneous fat necrosis of the newborn: a systematic evaluation of risk factors, clinical manifestations, complications and outcome of 16 children. Br J Dermatol 2007; 156(4): 709-715.

[5] Sindhurakasturi, Patra LB, Sethi RK, Patra DP. A case report on subcutaneous fat necrosis in newborn. J Evidence Based Med Healthcare 2014; 1(10): 1329-1331.

[6] Strohm B, Hobson A, Brucklehurst P, Edwards AD, Azzopardi D. Subcutaneous fat necrosis after moderate therapeutic hypothermia in neonates. Pediatrics 2011; 128 (2): 450452.

[7] Singalavanija S, Limponsanurak W, Wannaprasert T. Subcutaneous fat necrosis of the newborn. J Med Assoc Thai 2007; 90(6): 1214-1220.

[8] Beuzeboc Gérard M, Aillet S, Bertheuis N, Delliere $V$, Thienot S, Watier E, Surgical management of subcutaneous fat necrosis of the newborn required due to a lack of improvement: a very rare case. Br J Dermatol 2014; 171(1): 183-185. 


\title{
تقريرعن حالة شديدة وغيرعاد ية لنخر الاهون في عمر حديثي الولادة
}

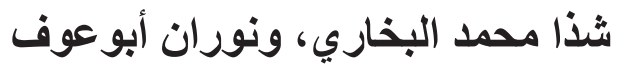

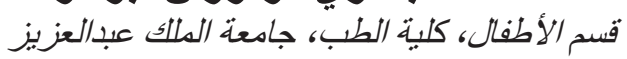

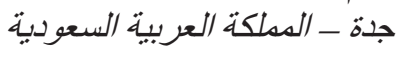

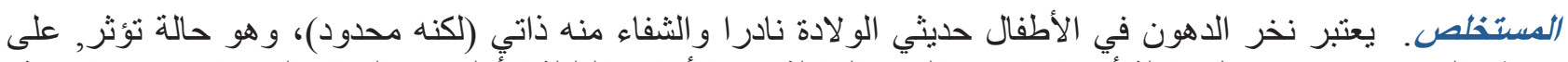

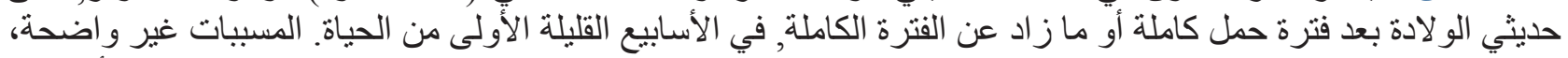

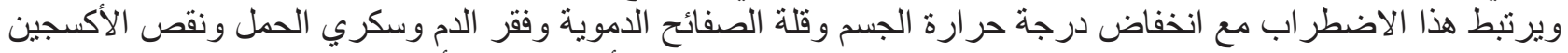

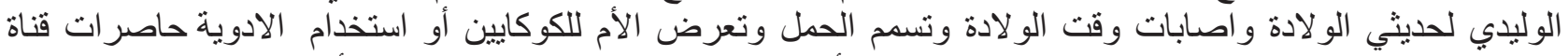

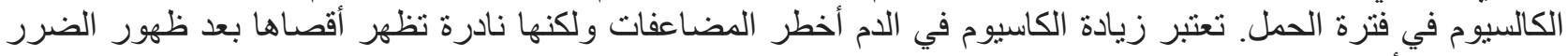

الجلاي بسنة أنثهر. 